\title{
АНТРОПОЛОГИЯ
}

DOI: $10.17805 / \mathrm{ggz} .2017 .2 .2$

\section{Самобытие человека в социальном мире: экзистенциально-антропологический подход}

\author{
А. С. АЛЕХНОВИЧ \\ РОССИЙСКАЯ АКАДЕМИЯ НАРОДНОГО ХОЗЯЙСТВА \\ И ГОСУДАРСТВЕННОЙ СЛУЖБЫ ПРИ ПРЕЗИДЕНТЕ РФ
}

В статьеанализируется проблема дуализма социального и экзистенциального в человеческом существовании. В ходе исследования выявляются онтологические основания для возможности самобытия человека в социальном мире. Автором предлагается экзистенциально-антропологический подход, раскрывающийся в бытийном мышлении и устремленный на исследование отношение человека к своему бытию. Автор исходит из понимания единства само-бытия и бытия-с-другими как ускользающих проявлений мирности (жизненный мир) в социальном мире.

Ключевые слова:экзистенция; самобытие; присутствие; деятельность; действительность; социальный мир; жизненный мир; личность; проект

\section{Self-being of the human social world: an existential-anthropological approach}

\author{
A. S. ALEKHNOVICH
}

RUSSIAN ACADEMY OF NATIONAL ECONOMY AND STATE SERVICE UNDER THE RF PRESIDENT

The article analyzes the problem of social and existential dualism in human existence. The study revealed the ontological foundation for the possibility of human self-being in the social world. The author suggests the existential-anthropological approach, revealed in existential thinking and looking to explore the relationship of man to his existence, author proceeds from the understanding of the unity of self-being and being-with-others as elusive worldfulness manifestations (lifeworld) in the social world.

Keywords: existence; self-being; presence; activity; reality; social world; lifeworld; social imaginary; identity; project

Человек в своем существовании открывает себя в исходной ситуации бытия-в-мире. Согласно экзистенциальным аналитикам, человек присутствует в трех модусах мироотношения: биологическом (die Umwelt, окружающий мир), социокультурном (die Mitwelt, совместный мир с другими) и экзистенциальном (die Eigenwelt, мир самости) (Мэй, 2004). Мир выступает проекцией человеческого присутствия, миропроектом как результатом конституирования индивидуального и социального опыта в различных способах данности. Мир - зеркало для осуществления человеческой субъективности, создающей структуры социального мира, к которому человек приспосабливается как к должному и неизменному порядку вещей.

В истории философии и гуманитарных наук принято считать, что социальное и человеческое сущее несоразмерны: первое как система функционирует на уровне ин- 
ститутов, второе как экзистенция существует на уровне личностей (коэкзистенция присутствий). Указанная дихотомия делается очевидной при концептуализации таких ущербных модусов со-бытия с другими, как одиночество и отчуждение, и безликости как онтической модификации самобытия в мире.

Аеятельностное понимание человека и общества оборачивается трактовкой социального как технического (техносоциального), отсюда - социальные технологии и технократии, «научное управление обществом» и социальное проектирование. $\mathrm{Pa-}$ ционалистическое конструирование социальных практик через целеполагание, планирование и управление (социальное проектирование) может подавлять возможности отдельных человеческих существований (экзистенциальное проектирование).

Из этой ситуации противоречия и попыток гармонизации социального и экзистенциального в человеке становится видна цель настоящей статьи - выявление и анализ онтологических оснований для возможностей самобытия человека в социальном мире. В своем исследовании мы постараемся избегать крайностей субстанцианализма и конструктивизма при обращении к используемому нами экзистенциально-антропологическому подходу. В первом случае существование означает подведение под сущность, и тогда сущность человека ищут в социальном, а сущность социального - в деятельности или коммуникации. Во втором случае существование означает быть построенным в понятии, что открывает дорогу проектно-конструктивистскому подходу в современной эпистемологии, когнитивных науках и науках о человеке (эпистемологический конструктивизм и социальный конструкционизм) (Иекторский, 2009).

Человеческое сущее начинается с различения себя-в-мире и сцепления себя-с-миром в миро-настроенности (базового доверия к миру). Бытие-в-мире раскрывается как общее жизненное отношение человека к бытию всего сущего, эксплицируемому в трансценденции к Иному. Если различение может указывать на отчуждение от мира, то сцеплением с миром является стремление к партиципации с универсумом. По определению отечественного философа-культуролога А. А. Пелипенко, партиципация - «универсальная экзистенциальная интенция, органически присущая человеку» (Пелипенко, 2012: 269), который настроен на восстановление эмпатической связи с миром и слияние с Иным (естественно-непротиворечивое состояние человеческого существования). Противоположным состоянием партиципации выступает отчуждение, которое находит свое выражение в оппозициях я и Иное в облике Аругого, противоречиях системного и жизненного в человеческом обществе, социально-экзистенциальном антагонизме в целом. Крайней формой отчуждения выступает смерть - отчуждение существования от существующего.

Развитие социальных теорий от макроанализа социальных систем к микроанализу человеческого существования в обществе способствовало появлению в 1960-х годах экзистенциально ориентированной социологии, представители которой предлагали рассматривать социальное как модель для осмысления экзистенциального и экзистенциальное как модель для понимания социального. Как экзистенциальная проекция опрокидывается на социальное, так и социальная проекция обращается на экзистенциальное бытие человека. Центральной категорией этого направления исследований является социетальная экзистенция, которая определяется как «бытие-в-обществе», т. е. «внутренняя экзистенциальная структура человеческого бытия» (Тирикьян, 2007: 76). Социетальная экзистенция соотносится с эмпирическим индивидом, в котором реализуется в единстве его самосознания и сознания других в совместно переживаемом опыте (Мельников, 2007). Так понятая экзистенция относится к субъективно-со- 
циетальному уровню общества, в котором выделяется интерсубъективная әкзистенция. Перенос экзистенциальных структур на социетальные дает приращение традиционных социологических понятий: аутентичное существование общества понимается как солидарность, неаутентичное, в свою очередь, - как аномия.

Как пишет польский социолог П. Штомпка, «идея социальной экзистенции сфокусирована на реально происходящее в обществе людей, на уровне между структурами и действиями, где ограничения структур и динамика действий производят реальные, проживаемые и наблюдаемые социальные события, социально индивидуальные практики, составляющие повседневную жизнь, фактически - единственную жизнь, которая есть у людей, и которая ни полностью детерминирована, ни полностью свободна» (Штомпка, 2009: 4-5). Такой поворот к повседневной жизни исследователь называет социологией социального существования как поколения третьей социологии, пришедшей на смену второй социологии социальных единиц (действий) и первой социологии социальных целостностей (систем).

Аля философско-антропологического анализа бытия человеческого сущего важно обращение к социальной философии, которая устремлена на познание всеобщего, но в специфическом видении социального сущего в его бытии. Методом социальной философии, или, вернее, способом раскрытия смысла всеобщего в его бытии, является феноменологическая онтология социального. Когда мы говорим о смысловой определенности многообразия сущего, мы выводим изменчивое сущее к его бытию через дифференциацию сущего по способу его бытия. Социальное бытие - концепт, который предполагает выделение особой области сущего в его бытии. Однако бытие едино в отличие от многообразия сущих, поэтому можно говорить лишь об онтологических регионах бытия сущего. Таким образом, социальная философия может рассматриваться как региональная онтология общества, основной вопрос которой о смысле и бытийной конституции социальной действительности как опыте совместного человеческого бытия. В свою очередь, региональная онтология размыкает и тематизирует действительность как тот или иной регион бытия, который является возможной предметной областью науки. Социальность до теоретического объяснения и после такой процедуры - разные предметности по своей смысловой структуре. Иными словами, социальная философия, находясь в сопряжении между философией с ее основным вопросом о бытии (фундаментальная онтология) и социологией (теоретической и эмпирической), пытается ухватить и концептуально промыслить социальное в социуме и человеке до того, как понимание социальности перейдет к теоретической понятийности социологии.

Обращаясь к вопросу об основании социальной реальности, зададимся предварительным вопросом: социальность и взаимодействия людей - что первичнее? Что определяет что? Перефразируя Э. Кассирера, можно спросить: опыт социальной жизни предваряет понятие социального генетически или логически понятие социального определяет опыт социальной жизни? Не инкорпорируем ли мы понятие социального в социальное тело априори? Аеятельность априорно включает целеполагание, следовательно, мышление и волю. Социальное вырастает как функция и отражение разумной деятельности, общественной практики. Социльное появляется из человеческих взаимодействий, а человеческое возникает в самом процессе этих взаимодействий. Чтобы появилось социальное, взаимодействия должны быть человеческими, человеческое же само появляется из этих взаимодействий, которые фундирует социальное. Где же начало этого круга? Аеятельностный подход (1) предполагает, что «смысл по- 
нятий и человеческих представлений порождается характером деятельности и представляет собой результат ее опредмечивания» (Энциклопедия эпистемологии.., 2009: 177). Аеятельность фундирует и организует человеческое общество, а что определяет и фундирует саму человеческую деятельность как целеполагающую разумную активность? Чтобы появилось общество, нужна деятельность, в которой уже присутствуют характеристики человеческой разумности, а ведь эта разумность уже есть результат возникновения человеческого общества!

Основа понимания сочиальной реальности - не деятельность, а действительность ситуачии человеческого со-присутствия 8 мире, причем мир может пониматься и описываться в разномасштабной реальности - от космоса до телесности. Неструктурированный и неартикулированный характер понимания человеческой ситуации не позволяет анализировать этот целостный феномен на языке эксплицитной научной теории. Наоборот, всякая теория уже вписана в эту изначальную ситуацию, как бы она ее не пыталась игнорировать.

Аействительность - модальность присутствия бытия, возможность - модальность присутствующего отсутствия (еще-не-настоящего) или отсутствия, которое показывает себя в присутствии бытия. Возможность есть отсутствие бытия, из которо-

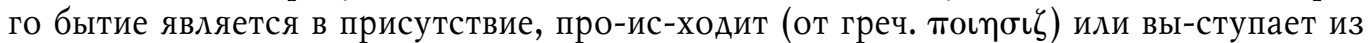
своей основы, которая может быть названа событием (Ereignis). Событие - это не только различение между человеческим сущим (Dasein) и его бытием (Existenz), но и еще различение бытия как становления и сущего бытия внутри самого бытия. Аобавим, что само-различение бытия предполагает, что в этом процессе следует различать то, что различается (бытие), и то, что различает указанное различие (присутствие), которое, в свою очередь, различается относительно различенного (становление). Таким образом, «бытие и есть отношение к самому себе, точнее - присутствиеесть само-различение» (Комаров, 2012: 19).

Событие как исток различающего себя бытия необходимо отличать от со-бытия как экзистенциала человеческого присутствия Dasein. Бытие-в-мире не отделимо от со-бытия с другими (Mit-Sein), или бытия-друг-с-другом. Со-присутствие (Mit-Dasein) образует совместный мир, значение которого открывается изначально и исключительно в повседневном со-бытии: «присутствие экзистенциально определено со-бытием и тогда, когда другой фактично не наличен и не воспринят» (Хайдеггер, 2013: 120). В со-бытии человеческое сущее может размыкать для себя свое собственное потенциальное бытие, которое осуществляется как «счистка сокрытий и затемнений, как взлом искажений, какими присутствие запирается от самого себя» (там же: 129).

Хайдеггер периода «Бытия и времени» указывает на разноплановость онтологических понятий, характеризующих существование (экзистенциалы), и онтических понятий, характеризующих деятельность (категории). Он избегает использования категории «деятельность» как онтологического лжепонимания присутствия и предлагает экзистенциалы «бытие-в-мире», «забота» и «решимость». Вместе с тем Хайдеггер делает попытку заново осмыслить существо деятельности: «Аюди видят в деятельности просто действительность того или иного действия. Его действенность оценивается по его результату. Но существо деятельности в осуществлении. Осуществить значит: развернуть нечто до полноты его существа, вывести к этой полноте, producere - про-из-вести» (Хайдеггер, 1993: 192). Тем самым философ фиксирует неразработанность проблемы деятельности применительно к онтологии человеческого существования. 
По словам современного исследователя, «деятельность невозможна без человеческой способности в какой-либо форме иметь отношение существования к самому себе» (Поросенков, 2002), а значит - без свободы осознания и понимания предпосылок мышления и деятельности. Понимать свое существование (самопонимание) означает предпонимание существования по отношению совершаемых действий, до любых действий, но осуществлять свое существование (самобытие) - эк-зистировать к бытию - значит осуществлять себя деятельно в присутствии с другими. И далее: «открытость человеческого существования себе и событие выражения этой открытости каким-либо способом есть совпадение существования и деятельности» (там же). Но это тождество содержит и различие экзистенциальной и деятельной сторон: «исток и возможность деятельности заключены в способности человеческого существования открыть себя и открыть существование всего иного, но открыть существование можно лишь в действии, включая действие отрицающее существование» (там же). Таким образом, осуществленная деятельность отрицает давшее ей действительность существование, которое всегда ускользает от своих объективаций в актах самоотрицания.

Сартр писал, что человеческая реальность, присутствующая по способу бытияАля-себя (самоотрицание, или ничтожение бытия-в-себе), постоянно колеблется между двумя разновидностями своего способа бытия: быть тем, чем он не является или не быть тем, чем он является, окончательно не совпадая в своем бытии со своими проекциями. Поэтому цель экзистенциального проектирования возможного в бытии человека не может быть достигнута не только потому, что человек конечен, но и потому, что ее реализация сопряжена с объективациями, которые ввергают его в несобственный способ бытия-в-себе (бытие социальной вещью среди других вещей) и отдаляют от себя. Человек, создавая структуры различного порядка, одновременно и преодолевает их в своей ориентации по отношению к возможному.

Онтологический смысл свободы для человека - без политических аспектов этого понятия - освободиться от всех принуждающих его сил, обеспечивающих его целями и смыслами, кроме одной силы - власти над самим собой, которая становится предметом его заботы (cura sui, «забота о себе»). Это свобода не от принуждения и контроля, а для того, чтобы не зависеть от внешних сил в своих возможностях. Быть свободным - значит мыслить возможное (феномен бытия) за пределами ограничивающих сил (трансфеноменальное бытие Иного). Но быть свободным - это также осуществлять себя в бытии-с-другими (забота о других), но не в бытии-для-другого (бытие объектом, присваиваемым Аругим, по Ж.-П. Сартру). Свобода - возобновляемая возможность быть самим собой, поэтому она осуществляется в событийной историчности человеческого существования. Быть самим собой (быть способом собственного бытия) - это не значит стать кем-то, это значит перестать пытаться быть чем-то, чем человек не является, т.е. перестань быть Аругим. Человеческое сущее есть возможность большего, то есть того, чем он может стать, но и невозможность большего, то есть того, чем он уже не станет.

K. Ясперс, анализируя положение человека в массовом обществе XX века, писал: «Индивид распадается на функции. Быть - означает быть в деле. Там, где ощущалась бы личность, деловитость была бы нарушена. Отдельный человек живёт как сознание социального бытия. В пограничном случае он ощущает радость труда без ощущения своей самости; живет коллектив, и то, что отдельному человеку казалось бы скучным, более того, невыносимым, в коллективе он спокойно принимает, как бы под властью иного импульса. Он мыслит своё бытие только как «мы»» (Ясперс, 1994: 309). К началу 
XXI столетия на смену массовому человеку-индивидууму как неделимой и автономной целостности (атомный уровень) приходят «дивидуумы» (Аелез, 2004) (субатомный уровень) - персонажи, рассеянные в информационном пространстве социума и делимые на огромное количество идентичностей, манифестаций и социальных ролей, которые взаимодействуют между собой по сетевому принципу. В историческом плане одним из первых, кто описал такую трансформацию, был Хайдеггер: «создание такого человечества, которое находит свой сущностный облик уже и не в “индивидууме", и не в “массе", но в “типе”. Тип объединяет в себе, видоизменяя, и неповторимость, ожидавшуюся раньше от индивида, и единообразие и универсальность, каких требует общество. Но неповторимость “типа” заключается во впечатляющей заразительности одинакового штампа, не терпящего вместе с тем никакой скучной уравниловки и нуждающегося, наоборот, в своеобразной иерархии...» (Хайдеггер, 1993: 120).

Мы входим в общество возможностей, в котором человек затянут на орбиту «индустрии возможностей», производство которых зависит от бесперебойного функционирования социальной системы. Человек оказывается окруженным со всех сторон опциями, позволяющими ему переключаться из одной возможности к Аругой: «изобилие благоприятных возможностей заставляет человека выбирать из существующего меню, ненавязчиво останавливает сознание на том, что есть» (Гречко, 2009: 282). Когда все становится возможностью, а свобода в социальном мире реализуется при выборе предустановленного набора возможностей, для человека закрывается трансценденция как исторический горизонт его экзистенции. Супермаркет готовых возможностей исключает доступ к самим возможностям.

Возможности, теряющие необходимую (аподиктическую) связь с действительностью, становятся не имеющими отношения к бытию псевдовозможностями. В этом смысле необходимость определяет отношение и переход между действительностью как всегда-уже-бытием и возможностью как еще-не-бытием. Человеческое сущее как бытие вот-бытия «представляет собой единство фактичности и экзистирования (заброшенности и проективности). Последние имеют отчетливо выраженный временной характер, и их единство осуществляется как экстатическое движение «забегания вперед» (Vorlaufen), предвосхищения своего будущего бытия в наброске - и «возвращения назад» (Zurückkommen), к своей фактичности, т. е. к той определенности собственного бытия, которая есть уже, «de facto» (Борисов, 1997: 88). Под фактичностью (экзистентное понимание) мы будем подразумевать порядок осуществления деятельности, а под проективностью (экзистенциальное понимание) - событие осуществления возможностей («прыжок в бытие», по выражению Хайдеггера). В отличие от социального проектирования, онтически закрывающего горизонт трансцендирования Аля вот-бытия, экзистенциальная проективность осуществляется как обмен бытийными возможностями в со-бытии с Аругими.

Как уже указывалось, одним из измерений человеческого бытия является социокультурный мир, однако его пространство неоднородно. Различают жизненный мир с культурными феноменами (повседневность) и социальный мир с формально организованными институтами и овеществленными объектно-онтическими отношениями (системность). Среди межличностных единений, озабоченных ближайшим кругом повседневного общения, простираются пространства отдаленного социально-политического и социально-экономического порядка.

Что же собирает и удерживает людей вместе в-со-присутствии? В качестве ответа на этот вопрос мы предлагаем понятие «социального воображаемого». Катего- 
рия воображаемого стала известной в науках об обществе благодаря исследованиям Ж.-П. Сарта и Ж. Аакана и была разработана у К. Касториадиса, Б. Андерсона, Ч. Тейлора, А. Кампера, Й. Арнасона и других исследователей. Не утилитаризм удовлетворения натуральных потребностей, не экономические интересы, а общность чувства и переживания связывает людей в пространстве социального воображаемого. Еще Э. Аюркгейм употреблял метафору «божественного социального» для описания скрепляющей силы общества, а Г. Зиммель писал о том, что человеческие взаимоотношения - это религиозное явление, которое по форме мы могли бы сейчас назвать общей матрицей представлений. Общность - это чувство сопричастности трансцендентному, которое М. Маффесоли назвал «энергией имманентного трансцендентного» (Маффесоли, 1991).

Социальное воображаемое не есть коллективное сознание (например, синтетическое сознание-без-Я), так как сознание всегда индивидуально. Напомним, что экзистенциальная философия отрицала феномен общественного сознания: опыт «...мы не является ни интерсубъективным сознанием, ни новым бытием, которое возвышает и включает свои части в качестве синтетического целого наподобие коллективного сознания социологов» (Сартр, 2009: 628). Скорее, это - ансамбль локально резонирующих индивидуальных сознаний, результатом которого является появление трансперсональной реальности, мультиплицирующей отделенные от индивидуальных опытов сознания трансцендентные элементы - воспроизводимые и разделяемые смыслы. Совместный опыт воображаемого это еще и область возможного как социальное проектирование, получающее выражение в различных социальных объединениях - от сектантских до политических, имеющих своей целью «техническое» преобразование сущего в желаемом направлении.

Взаимные действия совершают и животные (например, груминг у приматов), но без презумпции сознания, осмысляющего любые проявления человеческой активности (в том числе такие маргинальные формы как безумие, девиации, деструктивное поведение) человеческие действия ничем бы не отличались от таковых у животных. Первичными актами сознания, выбрасывающего проекции воображаемого на мир, становятся схватывание и различение смыслов, а культуры - способность выделять и задавать значимости, буквально - давать всему свое место, онтически определять присутствие в универсуме. Способность сознания (продуктивная сила воображения, по И. Канту) трансцендировать за пределы наличного физического и биологического опыта (простой ориентации в окружающей среде) стала возможностью для появлению у человека мышления, а в человеческих сообществах - культуры (2). Социальная реальность как процесс активности людей есть воображаемая реальность, которая состоит из взаимосвязанных значений и дана в совместно переживаемых феноменах. Социальное существует только до тех пор, пока верят в его реальность и оно как сущее что-то значит для своих участников (Вульф, 2009). Таким образом, вместо того, чтобы субстанциализировать общество в практиках теоретических проекций, следует обратиться к достоверности со-присутствия человеческих экзистенций в мире.

Проблема дуализма социального и экзистенциального в человеке будет носить абстрактно-типологический характер, если не вписать ее в контекст исторического бытия, точнее, историчности жизненного мира. Аичный опыт человека рассматривается как исторический в смысле повседневности, в которой акты бытия приобретают значения конститутивных для личностной истории (индивидуально-исторического бытия). Иными словами, историчность является не просто горизонтно-темпоральной 
структурой бытия человека, но захватывает личный опыт совместного проживания и переживания в мире, в котором человек понимает себя как миро-историческое сущее (welt-geschichtlich, по М. Хайдеггеру). Мир для меня становится миром для нас, в котором раскрывается горизонт конституирования единения Я и Ты (Ich-Du-Einigkeit, по Э. Гуссерлю) (Новая философская энциклопедия, 2010: 291). Аля выходящего в жизненный мир Я Аругие обнаруживают себя по аналогии с моим присутствием, здесь-бытие приводится в-со-присутствие с другими.

Онтико-онтологическая структура, в которой движется человеческое сущее, включает размерности: физический мир вещей и организмов - социально-системный мир (неподлинная несобственная самопонятность) - жизненный мир повседневности (фактичность как подлинная несобственная самопонятность) - самостный мир экзистенции (проективность как осуществление самобытия) - трансценденция (слияние с Иным на границе миров). Авижение в этих размерностях не диахронное в логике иерархического восхождения от низшего к высшему, а синхронное: проективно раскрывая свою самость навстречу бытию, человек не покидает всех модусов своих мироотношений: «Мир принадлежит к бытию его самости как бытию-в-мире» (Хайдеггер, 2013: 146). В таком случае экзистенциальная проективность человеческого сущего - феномен возможного как интенция конечного сознания на движение бесконечного преодоления (трансгрессии) себя и мира. Если экзистенция - предельная возможность, то трансценденция - запредельная возможность, в которой сущее может актуализовать свое существование, не покидая целостности «человеко-мира» (Резник, 2016: 437).

Онтическими модификациями несобственной самопонятности являются неподлинное (возможность не быть самим собой, т. е. быть Аругим или за Аругого) и подлинное (возможность быть самим собой) существование. Подлинность не отрицает неподлинность, а включает ее в себя, и наоборот. Как подчеркивает Хайдеггер, «напротив, это повседневное обретение себя в пределах фактического экзистирующего страстного погружения в вещи может быть подлинным, в то время как всякое экстравагантное копание в душе может быть в высшей степени неподлинным или даже экзальтированно-патологичным» (Кузьмин, 2008: 156).

Как понимать личность человека? Категория личности развивалась в философии от онтотеологической (личность как субстанция) через этико-аксиологическую (личность как субъект этических актов) к феноменологической (личность как возможное в человеке) интерпретации (Аорофеев, 2014). Аичность - представленность ( «маска»,

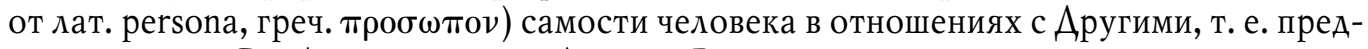
ставленность Я в Аругих и через Аругих. В социальном мире самость сталкивается с большим Аругим, в повседневном мире - со значимыми Аругими, с которыми самость входит в отношения взаимопроекций. Я личности отсылает к идентичности, которая разворачивается как тождество, возвращение к «тому же самому» (от лат. identitas). Это операции отождествления, или замещения и повтора, серийно подставляющие одно вместо другого. В таком отождествлении Я может полностью замещаться проекциями Аругих, ассиметричными двойниками личности, и тогда личность становится фантомом, знаком без содержания. Аичность - подвижный феномен, последовательно запускающий процедуры идентификации, модификации и трансформации собственного Я, которое выступает формой своей идентичности. Иными словами, вступающая в соприкосновение с социальным миром, субъективность Я порождает несовпадение идентичности «между наружным и изнанкой на основе институционально отформатированной наружности» (Сухачев, 1998). 
«Персона» личности сопрягает выделенную позиционность человека в мире и образ мира, с которым человек соотносится и от которого неотделим ( «сеть значимых интенций», по М. Мерло-Понти). В своей позиционности сталкиваясь с различными внутримировыми силами, человек удерживает мир на расстоянии (само-стоянии) и не принимает все налично-сущее подряд, но избирательно организует мир вокруг себя. Наконец, в этом смысле фигура Я есть социальная размерность индивидуального сознания, выраженная во внешнем мироотношении как социально обусловленное сущее (Резник, 2016: 248). Фигура и персона - онтические модификации фактического присутствия человеческой самости в социальном мире, без которых человек не может себя проявить как сущее.

В экзистенционально-феноменологической интерпретации личность - онтический феномен самораскрываемой самости, собранной в форме Я, которая, в свою очередь, является трансцендентным символом единства ускользающего от себя экзистенциального сознания. Самость человека, фундированная в изначальной ситуации бытия-в-мире и его модуса бытия-с-другими, обнаруживает и понимает себя из того, «на - что первичного наброска, из которого нечто как то, что оно есть, может быть понято в своей возможности» (Хайдеггер, 2013: 324). Самость разомкнута и открыта миру и себе в проективности своего бытия, которое понимается из возможностей собственной экзистенции. Таким образом, дуализм социального и әкзистенциального является условием возможности человеческого бытия-в-обществе.

Все изложенное позволяет говорить об использовании экзистенциально-антропологического подхода в социальной философии и философской антропологии, который направлен на раскрытие возможностей бытия человека в социальном мире как сплава фактичности и проективности человеческого со-присутствия. Экзистенциальная антропология концептуализирует феномены бытия персональной реальности человека, который присутствует в реальности социальной, наполняя бытийными возможностями повседневные лакуны социального мира. В отличие от социальной теории с ее научно-рационалистической методологией, антропологический подход (принцип) - интуитивно-феноменологический по своей методологической ориентации. Вне этого подхода находится многообразие сущностно-деятельностных направлений, детерминированных самой познавательной деятельностью (метадеятельность) и направленных на объяснение целостного сущего и положения в нем человека. Таким образом, экзистенциально-антропологический подход, раскрывающийся в бытийном мышлении (экзистенциальное сознание) и устремленный на исследование отношения человека к своему бытию, исходит из понимания единства само-бытия и бытия-с-другими как ускользающих проявлений мирности (жизненный мир) в социальном мире.

\section{ПРИМЕЧАНИЯ}

1. Аеятельностная парадигма включает такие направления, как «идеалистическая концепция деятельности классической немецкой философии, диалектико-материалистическая концепция деятельности в марксизме, философско-антропологическая концепция (А. Гелен), социологические концепции (М. Вебер, Т. Парсонс), праксиология Т. Котарбинского, психологические концепции (Ж. Пиаже, $\Lambda$. С. Выготский), бихевиоризм (Аж. Уотсон, Э. Толмен), операционализм (П. Бриджмен)» (Поросенков, 2002).

2. Человек своего рода - «метафизическое существо» (animal metaphysicum). Кант писал в этой связи о природной склонности человека к метафизическим спекуляциям (metaphysica naturalis), выходящим за пределы возможного опыта (Хайдеггер, 1993: 28). 


\section{СПИСОК АИТЕРАТУРЫ}

Борисов, Е. В. (1997) Аиалог как судьба. Со-бытие с Аругим в экзистенциальной аналитике М. Хайдеггера // История философии. Вып. 1. М. : ИФ РАН. С. 81-98.

Вульф, К. (2009) Генезис социального. Мимезис. Перформативность. Ритуал. СПб. : Интерсоцис. 164 с.

Гречко, П. К. (2009) Социальное: истоки, структурные профили, современные вызовы / под общ. ред. П. К. Гречко, Е. М. Курмелевой. М. : Российская политическая энциклопедия (РОССПЭН). 440 c.

Аелез, Ж. (2004) Post scriptum к обществам контроля // Переговоры. 1972-1990 / пер. с фр. В. Ю. Быстрова. СПб. : Наука. 235 с.

Аорофеев,А. Ю. (2014) Основные антропологические концепты: «самость», индивидуальность, субъект, личность // Экзистенциальный анализ. №6. С. 247-270.

Комаров, С. В. (2012) Различие как событие: возможность мышления // Вестник Пермского университета. Философия. Психология. Социология. Вып. 2 (10). С. 18-30.

Кузьмин, А. А. (2008) Рефлексивно-экзистенциальные основания понимания социальной реальности в философии М. Хайдеггера // Вопросы социальной теории: Научный альманах. T. II. Вып. 1 (2). С. 148-159.

Иекторский, В. А. (2009) Реализм, антиреализм, конструктивизм и конструктивный реализм в современной эпистемологии и науке // Конструктивистский подход в эпистемологии и науках о человеке / отв. ред. В. А. Аекторский. М. : «Канон+» РООИ «Реабилитация». 368 с.

Маффесоли, М. (1991) Околдованность мира, или Божественное социальное // Социо-Иогос. М. : Прогресс. С. 133-137.

Мельников, А. С. (2007) Социетальная экзистенция: за и против // Социология: теория, методы, маркетинг. № 1. С. 92-104.

Мэй, Р. (2004) Открытие Бытия. М. : Институт Общегуманитарных Исследований. 224 с.

Новая философская энциклопедия: в 4 т. (2010) / Ин-т философии РАН; Нац. Обществ.-науч. фонд; предс. Научно-ред. совета В. С. Степин. М. : Мысль. Т. 2. 634 с.

Пелипенко, А. А. (2012) Постижение культуры: в 2 ч. Ч. І. Культура и смысл. М. : Российская политическая энциклопедия (РОССПЭН). 607 с.

Поросенков, С. В. (2002) Существование и деятельность в определении ценностного отношения [Электронный ресурс]. Пермь : Изд-во Пермского гос. ун-та. 408 c. URL: http://hpsy.ru/ public/x1621.htm (дата обращения: 18.12.2016).

Резник, Ю. М. (2016) Феноменология человека: бытие возможного. М. : Канон+ РООИ«Реабилитация». $632 \mathrm{c.}$

Сартр, Ж.-П. (2009) Бытие и ничто: Опыт феноменологической онтологии. М. : АСТ. 925 с.

Сухачев, В. Ю. (1998) Пределы идентичности [Электронный ресурс]// Вестник Санкт-Петербургского университета. Серия 6. Спб. : Изд-во СПбГУ. Вып. 4 (№ 21). URL: http://anthropology.ru/ru/text/suhachyov-vyu/predely-identichnosti (дата обращения: 18.12.2016).

Тирикьян, Э. (2007) Социологизм и экзистенциализм // Вопросы социальной теории: Научный альманах. Т. І. Вып. 1. С. 50-84.

Хайдеггер, М. (1993) Время и бытие. М. : Республика, 1993. 447 с.

Хайдеггер, М. (2013) Бытие и время. М. : Академический проект. 460 с.

Штомпка П. (2009) В фокусе внимания повседневная жизнь. Новый поворот в социологии // Социологические исследования. № 8. С. 3-13.

Энциклопедия эпистемологии и философии науки (2009) М. : «Канон+» РООИ «Реабилитация». 1248 с.

Ясперс, К. (1994) Ауховная ситуация времени // Смысл и назначение истории. М. : Республика. 527 с.

\section{REFERENCES}

Borisov, E. V. (1997) Dialog kak sud'ba. So-bytie s Drugim v ehkzistencial'noj analitike M. Hajdeggera. In: Istoriya filosofii. Vyp. 1. Moscow, IF RAN. Pp. 81-98. (In Russ.) 
Vul'f, K. (2009) Genezis social'nogo. Mimezis. Performativnost'. Ritual. Sanct-Peterburg, Intersocis. 164 p. (In Russ.)

Grechko, P. K. (2009) Social' noe: istoki, strukturnye profili, sovremennye vyzovy/ pod obshch. red. P. K. Grechko, E. M. Kurmelevoj. Moscow, Rossijskaya politicheskaya ehnciklopediya (ROSSPEHN). 440 p. (In Russ.)

Delez, Zh. (2004) Post scriptum k obshchestvam kontrolya. In:Peregovory. 1972-1990 / per. s fr. V. Yu. Bystrova. Sanct-Peterburg, Nauka. 235 p. (In Russ.)

Dorofeev, D. Yu. (2014) Osnovnye antropologicheskie koncepty: «samost'», individual'nost', sub'ekt, lichnost'. Ekzistencial' nyj analiz. no. 6, pp. 247-270. (In Russ.)

Komarov, S. V. (2012) Razlichie kak sobytie: vozmozhnost' myshleniya. Vestnik Permskogo universiteta. Filosofiya. Psibologiya. Sociologiya. Vyp. 2 (10). pp. 18-30. (In Russ.)

Kuz'min, A. A. (2008) Refleksivno-ehkzistencial'nye osnovaniya ponimaniya social'noj real'nosti v filosofii M. Hajdeggera. Voprosy social' noj teorii: Nauchnyj al' manah. T. II, Vyp. 1 (2). pp. 148-159. (In Russ.)

Lektorskij, V. A. (2009) Realizm, antirealizm, konstruktivizm i konstruktivnyj realizm v sovremennoj ehpistemologii i nauke. In: Konstruktivistskij podbod v ebpistemologii i naukab o cheloveke. Otv. red. V. A. Lektorskij. Moscow, «Kanon+» ROOI «Reabilitaciya». 368 p. (In Russ.)

Maffesoli, M. (1991) Okoldovannost' mira, ili Bozhestvennoe social'noe. In: Socio-Logos. Moscow, Progress. Pp. 133-137. (In Russ.)

Mel'nikov, A. S. (2007) Societal'naya ehkzistenciya: za i protiv. Sociologiya: teoriya, metody, marketing, № 1, pp. 92-104. (In Russ.) Russ.)

Mehj, R. (2004) Otkrytie Bytiya. Moscow, Institut Obshchegumanitarnyh Issledovanij. 224 p. (In

Novaya filosofskaya ebnciklopediya: v 4 t. (2010) In-t filosofii RAN; Nac. obshchestv.-nauch. fond; Preds. Nauchno-red. soveta V. S. Stepin. Moscow, Mysl'. T. 2. 634 p. (In Russ.)

Pelipenko, A. A. (2012) Postizhenie kul' tury: v 2 ch. Ch. I. Kul'tura i smysl. Moscow, Rossijskaya politicheskaya ehnciklopediya (ROSSPEHN). 607 p. (In Russ.)

Porosenkov, S. V. (2002) Sushchestvovanie $i$ deyatel'nost' $v$ opredelenii cennostnogo otnosheniya. Perm' : Izd-vo Permskogo gos. un-ta. 408 p. [online] Avaible at: http://hpsy.ru/public/x1621.htm (access date: 18.12.2016). (In Russ.)

Reznik, Yu. M. (2016) Fenomenologiya cheloveka: bytie vozmozhnogo. Moscow, Kanon+ ROOI «Reabilitaciya». 632 p. (In Russ.)

Sartr, Zh.-P. (2009) Bytie i nichto: Opyt fenomenologicheskoj ontologii. M., AST. 925 p. (In Russ.)

Suhachev, V. Yu. (1998) Predely identichnosti. Vestnik Sankt-Peterburgskogo universiteta. Seriya 6. SPb.: Izd-vo SPbGU. Vyp. 4 (№ 21) [online] Avaible at: http://anthropology.ru/ru/text/ suhachyov-vyu/predely-identichnosti (access date: 18.12.2016). (In Russ.)

Tirik'yan, E. (2007) Sociologizm i ehkzistencializm. Voprosy social'noj teorii: Nauchnyj al' manah. T. I. Vyp. 1. pp. 50-84. (In Russ.)

Hajdegger, M. (1993) Vremya i bytie. Moscow, Respublika, 1993. 447 p. (In Russ.)

Hajdegger, M. (2013) Bytie i vremya. Moscow, Akademicheskij proekt. 460 p. (In Russ.)

Shtompka, P. (2009) V fokuse vnimaniya povsednevnaya zhizn'. Novyj povorot v sociologii. Sociologicheskie issledovaniya, № 8, pp. 3-13. (In Russ.)

Enciklopediya ehpistemologii i filosofii nauki (2009) Moscow, «Kanon+» ROOI «Reabilitaciya». 1248 p. (In Russ.)

Yaspers, K. (1994) Duhovnaya situaciya vremeni. In: Yaspers, K. Smysl i naznachenie istorii. Moscow, Respublika. 527 p. (In Russ.)

Аата поступления: 15.04.2017 2.

Алехнович Александр Сергеевич - аспирант кафедры философии философско-социологического факультета Института общественных наук Российской академии народного хозяйства и государственной службы при Президенте РФ (Москва). E-mail: alehnovich.san@rambler.ru 
Alekhnovich Aleksandr Sergeevich, post-graduate student, Department of philosophy, Faculty of Philosophy and Social sciences, School of Public Policy, Russian Presidential Academy of National Economy and Public Administration (RANEPA, Moscow).E-mail: alehnovich.san@rambler.ru

\section{Аля ицитирования:}

Алехнович А. С. Самобытие человека в социальном мире: экзистенциально-антропологический подход [Электронный ресурс] // Горизонты гуманитарного знания. 2017, №2. URL: http://journals.mosgu.ru/ggz/article/view/458 (дата обращения: Ад.мм.гггг.). DOI: 10.17805/ ggz.2017.2.2 